\title{
The planarian Schmidtea mediterranea as a model system for the discovery and characterization of cell penetrating peptides and bioportides
}

Short running title: A planarian model system for CPP discovery

Key words: Bioportide, Blastema, Cell penetrating peptide, Confocal microscopy, Eye regeneration, Peptide synthesis, Zinc finger

\section{Sarah Jones $^{1}$ Shaimaa Osman² John Howl ${ }^{1}$}

${ }^{1}$ Molecular Pharmacology Group, Research Institute in Healthcare Science, Faculty of

Science and Engineering, University of Wolverhampton, Wulfruna Street, Wolverhampton, WV1 1LY, UK.

${ }^{2}$ Peptide Chemistry Department, National Research Centre, Dokki 12622, Cairo, Egypt.

\section{Correspondence}

John Howl, Molecular Pharmacology Group, Research Institute in Healthcare Science,

Faculty of Science and Engineering, University of Wolverhampton, Wulfruna Street,

Wolverhampton, WV1 1LY, UK.

Email: $\quad \underline{\text { J.Howl@wlv.ac.uk }}$

Phone: $\quad+1902321131$

Fax: $\quad+1902322714$ 


\begin{abstract}
The general utility of the planarian Schmiditea mediterranea, an organism with remarkable regenerative capacity, was investigated as a convenient three-dimensional model to analyse the import of cell penetrating peptides (CPPs) and bioportides (bioactive CPPs) into complex tissues. The unpigmented planarian blastema, 3-days post head amputation, is a robust platform to assess the penetration of red-fluorescent CPPs into epithelial cells and deeper tissues. Three planarian proteins, Ovo, ZicA and Djeya, which collectively control head remodelling and eye regeneration following decapitation, are a convenient source of novel cationic CPP vectors. One example, Djeya1 (RKLAFRYRRIKELYNSYR), is a particularly efficient and seemingly inert CPP vector that could be further developed to assist the delivery of bioactive payloads across the plasma membrane of eukaryotic cells. Eye regeneration, following head amputation, was utilised in an effort to identify bioportides capable of influencing stem-cell dependent morphogenesis. These investigations identified the tetradecapeptide mastoparan (INLKALAALAKKIL) as a bioportide able to influence the gross morphology of head development. We conclude that, compared with cellular monolayers, the $S$. mediterranea system provides many advantages and will support the identification of bioportides able to selectively modify the biology of totipotent neoblasts and, presumably, other mammalian stem cell types.
\end{abstract}




\section{INTRODUCTION}

The plasma membrane of eukaryotic cells generally acts to limit the intracellular accumulation of polar macromolecules, so restricting the target-specific access and efficacy of putative therapeutic agents. As summarised elsewhere, ${ }^{[1-3]}$ cell penetrating peptides (CPPs), usually short ( $<25$ amino acids) polycationic sequences, have tremendous potential to deliver bioactive cargoes, including macromolecular therapeutics, as both covalent and non-covalent complexes. Bioactive CPPs, or bioportides, ${ }^{[4,5]}$ can directly modulate the activities of intracellular proteins often by a dominant-negative influence upon proteinprotein interactions. ${ }^{[6]}$ Moreover, it is obvious that, in order to achieve a selective influence upon cells and tissues in vivo, CPP vectors and bioportides might need to traverse the physical impediments of both cutaneous and mucous membranes and those cellular barriers that enclose body cavities and immunologically privileged organs including brain and testis. More recently, a variety of innovative CPP technologies have been developed that, individually and collectively, serve to negate some of the challenges posed by diverse physiological barriers. ${ }^{[7-10]}$ Nevertheless, and despite many recent advances, a simple, reliable and robust system to evaluate CPP and bioportide import into complex tissues would be a useful adjunct to more complex in vivo assays; this objective was the starting point for this study.

The triploblastic bilateral planarian Schmiditea mediterranea, a free living representative of the phylum Platyhelminthes, is a model organism employed for studies of developmental cell biology, regeneration, embryology and stem cell function. ${ }^{[11-16]}$ The study of such fundamental biological processes is further aided by a comprehensive $S$. mediterranea genomic database (SmedGD 2.0) ${ }^{[17]}$ which enables data mining of both the genome and transcriptome. As previously discussed by others, ${ }^{[11-13]}$ planaria offer many advantages as a model organism that include: i) the ability to fully regenerate complete 
animals only days after amputation, ii) ease of maintenance, and iii) the presence of large numbers of adult stem cells. Moreover, there are surprising similarities between planarian proteins and those expressed in higher vertebrates; examples include $\mathrm{G}$ protein-coupled receptors, ${ }^{[18]}$ numerous determinants of pluripotency ${ }^{[19]}$ and transcription factors encoded by ovo and mammalian orthologs. ${ }^{[20]}$ Many bioactive peptides, some of which are homologues of mammalian hormones and neuropetides, regulate planarian physiology, regeneration and development. ${ }^{[21-23]}$ The demonstrated influence of exogenously applied tachykinin analogues upon stem cell proliferation ${ }^{[14]}$ provides further compelling evidence that planarians utilise peptide signalling pathways analogous to those in higher organisms. Moreover, the same study confirmed that exogenously applied peptides were able to access receptors expressed on their target cells having passed through a protective mucous layer now recognised to be remarkably similar to human mucosal secretions. ${ }^{[24]}$ Thus, we undertook the investigations described herein partly to evaluate $S$. mediterranea as a model system to study CPP and bioportide import in the presence of both physical and metabolic barriers and so address some of the challenges of targeted drug delivery in vivo. ${ }^{[10,25]}$

A related goal of this investigation was to determine some biochemical properties of mimetic peptides derived from cationic domains of planarian proteins. Many human proteins which bind RNA and DNA possess readily-identifiable poly-arginine sequences that are effective cationic CPPs. ${ }^{[26]}$ These polycationic domains may confer a ubiquitous membrane translocating mechanism to supercharged proteins. ${ }^{[26,27]}$ Indeed, the widely employed CPP vectors Tat ${ }^{[28]}$ and Penetratin ${ }^{[29]}$ derive from transcription factors that are required to traverse plasma membranes. Logically, the activities of transcription factors intimately regulate the remarkable regenerative processes in planaria. More specifically, a conserved network of nuclear proteins, better resolved in Drosophila, is essential for eye development in $S$. meditteranea and hints at a common ancestor for this process in metazoans. ${ }^{[20,30-32]}$ Thus, our 
studies focused upon three proteins, the products of genes, Djeyes absent $(\text { Djeya })^{[30]}$, ovo ${ }^{[20]}$ and ZicA $\left(\right.$ Zic-1) $1^{[31,32]}$, known to regulate anterior pole and eye regeneration in planaria. The Djeya protein contains an evolutionary conserved EYA domain that enables it to interact with other nuclear proteins to control eye morphogenesis. ${ }^{[33]}$ Both Ovo and ZicA proteins are transcription factors that contain 3 or $4 \mathrm{C} 2 \mathrm{H} 2$-type zinc finger (ZF) DNA-binding domains respectively. One objective was to study the cellular uptake of fluorescent planarian proteinderived CPPs and compare these with conventional CPPs derived from human proteins. This approach enabled the identification of the most efficient CPPs as delivery vectors for studies with multicellular planaria. A second objective of this study was to develop a platform to select bioportides which influence eye regeneration. Uniquely, the extreme regenerative capability of planarians is a consequence of an abundant ( 20-30\%) population of neoblasts, an adult pluripotent stem cell population capable of producing all other cell types, including germ cells. ${ }^{[11,12,34]}$ As reviewed elsewhere, ${ }^{[34]}$ neoblasts are relatively small (typically 7-12 $\mu \mathrm{m})$, morphologically undifferentiated cells with a strongly basophilic cytoplasm. As the only planarian cell type capable of proliferation, neoblasts are a remarkable stem cell model. Thus, CPP technologies capable of selective delivery to neoblasts within a syncytial parenchymal cell mass would offer clear advantages for the in vivo targeting, genetic manipulation and reprogramming of stem cells perhaps mediated by the delivery of proteins or oligonucleotides. ${ }^{[35,36]}$ Such advancements will also underpin the development of technologies to study and manipulate stem cell function through the generation of transgenic organisms and related genetic approaches. ${ }^{[34,37]}$ 


\section{METHODS AND MATERIALS}

\subsection{Planarian culture}

Specimens of S. mediterranea, hermaphroditic sexual strain, were a kind gift from Kerstin Bartscherer (Max Planck Institute for Molecular Medicine, Münster, Germany). Animals were maintained at $18-20^{\circ} \mathrm{C}$ in planarian artificial medium (PAM) containing $\mathrm{NaCl}(1.6 \mathrm{mM})$, $\mathrm{MgSO}_{4}(1 \mathrm{mM}), \mathrm{MgCl}_{2}(0.1 \mathrm{mM}), \mathrm{KCl}(0.1 \mathrm{mM}), \mathrm{NaHCO}_{3}(1.2 \mathrm{mM})$ and $\mathrm{CaCl}_{2}(1 \mathrm{mM})$ in ultrapure water with gentamycin $(3 \mu \mathrm{g} / \mathrm{ml}) .{ }^{[38]}$ For convenience, stock solutions were prepared at 100X (PAM w/o $\left.\mathrm{CaCl}_{2}\right)$ and $200 \mathrm{X}\left(\mathrm{CaCl}_{2}\right)$ and stored at $4{ }^{\circ} \mathrm{C} \cdot \mathrm{CaCl}_{2}(200 \mathrm{X})$ was added separately so as to avoid precipitation out of solution. Animals were routinely fed, three times a week with finely minced bovine liver and ethically-sourced Icelandic cod (Waitrose). Planaria whose size reached 4-6 $\mathrm{mm}$ in length were selected for experimentation and, whence appropriate, starved 5 days prior to amputation.

\subsection{Microwave-enhanced peptide synthesis}

The syntheses of a majority of CPPs and bioportides used in this study have been described elsewhere as reported in Table 1. Mimetic peptides derived from three planarian peptides were manufactured using microwave-enhanced peptide chemistry on a CEM Liberty Blue instrument equipped with UV analyser to determine coupling efficiencies. ${ }^{[39]}$ De novo peptides were synthesized ( 0.1 mmole scale) on Rink Amide 4-Methylbenzhydrylaamine (MBHA) cross-linked polystyrene resins (Novabiochem) to generate peptide amides. Routine amino acid coupling at $90^{\circ} \mathrm{C} / 120 \mathrm{~s}$ in Dimethylformamide (DMF) employed N,N'Diisopropylcarbodiimide (Sigma) as the condensation reagent with the additive Ethyl 2cyano-2-(hydroxyimino)acetate (Oxyma). ${ }^{[40]}$ Special coupling cycles were employed for Arg, 
double coupling $75^{\circ} \mathrm{C} / 300 \mathrm{~s}$, and $\mathrm{Cys} / \mathrm{His}$, single coupling $50^{\circ} \mathrm{C} / 600 \mathrm{~s}$, to reduce $\delta$-lactam formation of Arg and racemisation of Cys/His respectively. A standard deprotection cycle with $20 \%$ (v/v) Piperidine in DMF was $90^{\circ} \mathrm{C} / 60$ s monitored by determining the UV absorption at $301 \mathrm{~nm}$ of Dibenzofulvene-piperidine adducts. ${ }^{[39]}$

Amino-terminal acylation of peptides with 6-Carboxytetramethylrhodamine (Novabiochem) produced fluorescent peptides for confocal microscopy and quantitative uptake studies. All de novo peptides described herein were purified to apparent homogeneity by reverse phase HPLC and analysed by mass spectroscopy to confirm their identity (Table $1) .^{[5]}$

\subsection{Blastema formation and eye morphogenesis following treatment with}

\section{bioportides}

Transverse amputation of planaria at the post-auricle and pre-pharynx level (Figure 1) induced blastema leading to eye regeneration and head remodelling. Amputation was performed in a $150 \mathrm{~mm}$ diameter $\mathrm{x} 25 \mathrm{~mm}$ depth culture dish (Corning) containing filtersterilized PAM and used an ethanol-sterilized scalpel to minimize contamination at the site of the wound. To ensure accuracy in selection of the amputation site, a jewellers' magnifier was employed. Following amputation, planaria were treated immediately with $25 \mu \mathrm{M}$ bioportides or the positive control U1026 (10 $\mu \mathrm{M}$ and $25 \mu \mathrm{M}$; Calbiochem) in PAM in $35 \mathrm{~mm}$ diameter $\mathrm{x}$ $10 \mathrm{~mm}$ depth culture dishes (Corning) to a final volume of $4 \mathrm{ml}$ and maintained at $18-20^{\circ} \mathrm{C}$. A $0.25 \%(\mathrm{v} / \mathrm{v})$ DMSO control was included owing to the final assay concentration of DMSO when using $25 \mu \mathrm{M}$ U1026. Those planaria treated with peptides underwent further treatments at 24 hours and 4 days post amputation to allow for temporal variation in both gene

expression and protein signalling. ${ }^{[31,41,42]}$ Additionally, multiple treatments with bioportides 
circumvented any potential premature proteolysis of exogenously applied peptides. Treated planaria were allowed to regenerate for 7 days post amputation, whilst observations were performed daily to assess any morphological variations. Thereafter, planaria were transferred to a $24-w e l l$ plate (1 planaria per well) in which they were immobilized, depleted of mucous and euthanised with $\mathrm{N}$-acetylcysteine $(5 \% \mathrm{w} / \mathrm{v})$ in phosphate-buffered saline (PBS) at room temperature. Prolonged periods of treatment with $\mathrm{N}$-acetylcysteine were avoided so as to avoid tissue damage. Immobilized planaria were transferred to fresh PBS and viewed with a Nikon Eclipse TS100 microscope equipped with a Nikon Digital-Sight camera. Images were captured using $\mathrm{x} 4, \mathrm{x} 10$ or $\mathrm{x} 20$ objectives (Figure 1 ).

\subsection{Intracellular accumulation of TAMRA-labelled CPP and bioportides in cells of the blastema: Preparations for confocal microscopy.}

Transverse amputations of planaria were performed as described above and beheaded specimens were maintained in PAM for 3 days at $18-20^{\circ} \mathrm{C}$ to allow for blastema formation

(Figure 1). Thereafter, planaria were transferred to a 24 -well plate (1 planarian per well) and treated with $1 \mu \mathrm{M}$ or $5 \mu \mathrm{M}$ TAMRA-labelled CPP or bioportide to a final volume of 1 $\mathrm{ml} /$ well for $1 \mathrm{hr}$. Following 6 washes with PAM, planaria were processed with $\mathrm{N}$ acetylcysteine $(5 \% \mathrm{w} / \mathrm{v})$ in phosphate-buffered saline (PBS) at room temperature for 5 minutes, fixed with $10 \%$ neutral buffered formalin solution containing $4 \%(\mathrm{w} / \mathrm{v})$ formaldehyde (Sigma) for 15-20 minutes at room temperature, then washed twice in PBS. Specimens were gradually dehydrated; treatment with 50\% (v/v) ethanol in PBS for 5-10 minutes at room temperature was replaced with $100 \%$ ethanol for 5-10 minutes. Specimens were transferred to $-20^{\circ} \mathrm{C}$ for long term storage of up to 6 months. Fixation methods are adapted from those described by Pearson and co-workers ${ }^{[43]}$ who also suggest that methanol may be substituted for ethanol. However, despite the former reported to give a superior 
signal, it is only recommended for short-term storage at $-20^{\circ} \mathrm{C}$. For initial experiments using whole planaria instead of the unpigmented blastema, specimens were removed from storage at $-20^{\circ} \mathrm{C}$ and placed in $6 \% \mathrm{H}_{2} \mathrm{O}_{2}(30 \%$ stock Sigma $)$ in ethanol and left overnight at room temperature. Thereafter, bleached specimens were returned to $-20^{\circ} \mathrm{C}$ in $100 \%$ ethanol. ${ }^{[43]}$

Prior to confocal microscopic analyses, specimens were rehydrated with $50 \%(\mathrm{v} / \mathrm{v})$ ethanol in PBS for 5 minutes at room temperature. Specimens were allowed to sink before replacement of $50 \%$ ethanol with PBS. ${ }^{[43]} \mathrm{PBS}$ was then replaced with $80 \%$ (v/v) glycerol in PBS and samples were transferred to slides and mounted under Zeiss high precision glass coverslips $(18 \mathrm{~mm} \times 18 \mathrm{~mm}$, thickness $170 \pm 5 \mu \mathrm{m})$. Specimens may be stored at $4^{\circ} \mathrm{C}$ in $80 \%$ (v/v) glycerol for 24 hours. Confocal analyses were performed using a Zeiss LSM 880 Microscope.

\subsection{Quantitative uptake analysis}

Many of our previous studies ${ }^{[39,44]}$ have employed the U373MG astrocytoma cell line as a robust model to quantify the degree of cellular internalization of CPPs and bioportides. $\mathrm{U} 373 \mathrm{MG}$ were maintained in a humidified atmosphere of $5 \% \mathrm{CO}_{2}$ at $37^{\circ} \mathrm{C}$ in $\mathrm{DMEM}$ supplemented with L-glutamine $(0.1 \mathrm{mg} / \mathrm{ml}), 10 \%$ (wt/vol) fetal bovine serum (FBS), penicillin $(100 \mathrm{U} / \mathrm{ml})$ and streptomycin $(100 \mu \mathrm{g} / \mathrm{ml})$. Following transfer to 6-well plates, cells were grown to $80 \%$ confluence, washed in phenol red-free DMEM and subsequently treated with TAMRA-conjugated peptides at a final concentration of $5 \mu \mathrm{M}$ for 1 hour in phenol redfree DMEM. Cells were washed four times, detached with $300 \mu \mathrm{l}$ of $10 \%$ (w/v) trypsin (without phenol red) at $37^{\circ} \mathrm{C}$, collected by centrifugation and lysed in $300 \mu 10.1 \mathrm{M} \mathrm{NaOH}$ for two hours on ice. Alternatively, samples may be stored at $-20^{\circ} \mathrm{C}$ at this stage, defrosted and assayed at a later date. $250 \mu \mathrm{l}$ of each sample cell lysate were transferred to a black 96- 
well plate, and analysed using a ThermoFischer Scientific Fluoroskan Ascent FL flurorescence spectrophotometer ( $\lambda$ Abs $544 \mathrm{~nm} / \lambda \mathrm{Em} 590 \mathrm{~nm})$.

\section{RESULTS}

\subsection{CPP and bioportide accumulation within planarian tissue}

To assess the propensity of CPPs and bioportides to penetrate planarian tissues, initial experiments were carried out using whole planaria, a methodology which required bleaching or tissue clearing of the whole organism (Section 2.4). However, of all CPPs tested during this initial screening, including transportan-10, ${ }^{[45]}$ mitoparan ${ }^{[46]}$ and inverso-mastoparan, ${ }^{[47]}$ only the bioportide nosangiotide ${ }^{[5]}$ gave a reliable and robust signal (Figure $2 \mathrm{a}$ ).

After injury, planarian neoblasts proliferate and migrate to the site of injury to form a mass of undifferentiated cells which later give rise to missing tissue. ${ }^{[48]}$ This unpigmented tissue mass, termed the blastema (Figure 1), provided us with a more convenient and robust model to explore the destination of TAMRA-labelled CPPs and bioportides using confocal microscopy, since the bleaching step was unnecessary and the signal to noise ratio was much improved (Figure 2). As highlighted in Figure 2, both the bioportide nosangiotide and the inert CPP vector C105Y, ${ }^{[49]}$ demonstrated a predominant accumulation in the outer epithelium layer of the 3 day old blastemal (Figure 2c, $d$ and e). Figure $2 b$ depicts the cellular populations of the planarian blastema, the outer epithelium, neoblast-derived mesenchymal cells and neoblasts. Early epithelialization following injury is derived from migration and shape modifications of pre-existing epidermal cells, ${ }^{[50]}$ though the wound epidermis is continually supplemented by precursor cells from the newly formed neoblast-derived blastema. ${ }^{[51]}$ Figure 2e highlights elongation of wound epidermal cells, which has been attributed to partial wound relaxation following initial contraction. ${ }^{[51]}$ Below the epithelium Figure $2 b$ additionally depicts neoblast-derived mesenchymal cells which will eventually 
differentiate into lost body parts ${ }^{[50]}$ and proliferating neoblasts, which during anterior head regeneration remain proximal to the blastema at the wound boundary. ${ }^{[52]}$ Confocal analyses taken at a lower optical $\mathrm{Z}$ plane along the blastemic dorsal-ventral axis (Figure 3a) established that both nosangiotide and $\mathrm{C} 105 \mathrm{Y}$ had moved beyond the initial epidermal layer (Figure $2 \mathrm{f}$ and $\mathrm{g}$ ). Accordingly, Figure $3 \mathrm{~b}$ shows the bioportide mastoparan (MP) at different $\mathrm{Z}$ planes through the dorsal-ventral axis of the blastema. TAMRA-MP reaches approximately $30 \mu \mathrm{m}$ into the blastema (approximate depth of the blastema along the dorsalventral axis $200 \mu \mathrm{m}$ ) from surface epithelial cells, though fluorescence intensity is reduced towards the lower limits of the $\mathrm{Z}$ axis.

\subsection{Design and synthesis of planarian-derived mimetic peptides}

The primary sequences of the planarian proteins Ovo (UniProtKB J7FM12 (J7FM12_SCHMD)), ZicA (UniProtKB - X5CWX3 (X5CWX3_SCHMD)) and Djeya (UniProtKB - Q86FY6 (Q86FY6_DUGJA)) were extracted from the UniProt Knowledgebase (UniprotKB; https://www.uniprot.org/). C105Y ${ }^{[49[}$ (Table 1) is a somewhat atypical though highly efficient $\mathrm{CPP}$ with a $\mathrm{Z}$ value of just 1.9 whilst $\mathrm{Tat}^{[28]}, \mathrm{Z}=9.0$, is a more "typical" highly polycationic sequence. Thus, in this study we sought to identify or design potential bioportides that were similar in length (16 AA) and net charge, $4<\mathrm{Z}<9$, to the anti-angiogenic peptide nosangiotide. ${ }^{[5]}$ Moreover, we restricted our search to rhegnylogically-organised bioportides, ${ }^{[4-6]}$ sequences in which the putative pharmacophores for both cellular penetration (address) and biological activity (message) are discontinuously organised within a single sequence.

In the case of Ovo and ZicA, the search for Arg- and Lys-rich sequences was restricted to annotated C2H2-type ZF domains (Table 1). Ovo1 ([Arg-Lys] $]^{0}-\mathrm{Ovo}{ }^{236-249}$ ) was designed as a mimetic of the first ZF domain of Ovo, extended at the $\mathrm{N}$-terminal with the 
dipeptide Arg-Lys based upon sequence homology with the third ZF domain to add additional cationic charge and so improve CPP efficacy. Chimeric-Ovo $\left(\mathrm{Ovv}^{291-295}{ }_{-} \mathrm{Ovo}{ }^{239-}\right.$ ${ }^{242}$-Ovo $^{271-277}$ ) combines cationic elements from all three ZF domains in a tandem construct that is a partial consensus sequence. Zica1 ([Leu $\left.{ }^{8}, \operatorname{Arg}^{14}\right] \mathrm{ZicA}^{280-295}$ is a mimetic of the third ZF domain of ZicA with Leu substituted for a problematic Asp at position-8 and Arg replacing His at position-14. These changes, based upon homology with other ZF domains from ZicA, were made to reduce the potential for aspartamide formation during synthesis and increase cationic charge density at the $\mathrm{C}$-terminal. $\mathrm{ZicA} 2\left(\mathrm{ZicA}^{220-235}\right)$ is a mimetic of the first ZF domain of the ZicA protein. Djeya1 (Djeya ${ }^{391-418}$ ), a slightly longer octadecapeptide, derives from a much larger conserved EYA domain of the Djeya protein from Dugesia japonica (Table 1). The EYA domain is believed to regulate gene transcription by participating in multiple protein-protein interactions. ${ }^{[30]}$

\subsection{Quantitative uptake analyses of planarian-derived mimetic peptides.}

We routinely utilize the U373MG astrocytic tumour cell line to quantitatively evaluate the penetrative propensities of CPPs and candidate bioportides. ${ }^{[39,44]}$ Thus, and as a comparative single cellular model, we determined the degree of cellular internalization of our rationallydesigned planarian-derived mimetic peptides. Most notably, Djeyal gave the greatest translocation efficacy of $3.80 \pm 0.09$ (data expressed as mean fluorescence minus background \pm S.E.M and normalized so that Tat $=1)$, even exceeding the established CPP C105Y $(3.47 \pm$ $0.08)$ and Tat $(1.00 \pm 0.03)$, (Figure 4). Translocation efficacies of the planarian-derived mimetic peptides were, in descending order, Chimeric-Ovo $(0.76 \pm 0.08)$, Ovo1 $(0.70 \pm 0.02)$, ZicA1 $(0.68 \pm 0.04)$ and ZicA2 $(0.34 \pm 0.02)$. As we have observed on numerous occasions within our laboratory, the bioportide nosangiotide preferentially accumulates within cells of 
endothelial origin. Accordingly, nosangiotide gave the lowest translocation efficacy of $0.06 \pm$ 0.007, (Figure 4).

A major determinant of the biological activity of MP is its ability to incorporate into biological membranes as an amphipathic $\alpha$-helix and present a region of cationic charge provided by Lysyl residues at positions 4,11 and 12. These cationic side-chains, together with the amino terminus, mimic the G-protein binding domain of $\mathrm{G}$ protein-coupled receptors (GPCRs). ${ }^{[53]}$ Consequently, MP is widely known as a receptor-independent activator of heterotrimeric $\mathrm{G}$ proteins. Moreover, when analysed using confocal live cell imaging, ${ }^{[46]}$ rather than accumulating within the intracellular milieu, MP largely remains incorporated into the outer plasma membrane, thus in this assay system, MP demonstrates a penetrative propensity of $2.5 \pm 0.19$.

\subsection{Qualitative confocal uptake analyses of planarian-derived mimetic}

\section{peptides}

TAMRA-labelled planarian-derived mimetic peptides, designed to target anterior pole and eye regeneration, were incubated with living planaria 3 days post amputation. As with nosangiotide, C105Y and MP, all TAMRA-labelled peptides accumulated within the epithelium of the anterior pole of the blastemal (Figure 5). Of particular interest is the observation that TAMRA-Djeya was additionally located in cellular populations at a lower optical plane along the dorsal-ventral axis and proximal to the wound boundary (Figure 5). Of further significance is the observation that all CPPs and bioportides in this study were able to cross the biophysical mucous barrier secreted by planaria. To establish this finding, we purposefully treated whole planaria and 3 day-old amputees with TAMRA-labelled peptides prior to the removal of mucous with $\mathrm{N}$-acetylcysteine (Section 2.4). 


\subsection{Evaluation of planarian anterior pole regeneration and eye development following treatment with candidate bioportides.}

Immediately following amputation, animals were treated with $25 \mu \mathrm{M}$ planarian-derived mimetic peptides and monitored for morphological changes over a 7 day period, a strategy which allowed sufficient time for eye regeneration (Figure 6). As previously detailed in Section 2.3, additional treatments at the same concentration were included to allow for temporal variations in both gene expression and protein signalling of the parent planarian protein from which the candidate bioportides were derived, whilst also compensating for premature proteolysis of the peptide constructs. Inhibition of extracellular signal-regulated kinase (ERK) activity was used as a positive control to perturb blastema cellular differentiation and eye regeneration. ${ }^{[54]}$ More specifically, Tasaki and co-workers report ${ }^{[54]}$ that ERK signalling is required for mitotic neoblasts to exit their proliferative state and undergo differentiation, whilst ERK inhibition resulted in severe defects in anterior pole regeneration such as a no eye phenotype and cyclopia. Thus, in accordance with previous reports, treatment of amputees with the MEK1/2 inhibitor U0126 impacted upon anterior pole regeneration (Figure 6). However, rather than observing serious eye defects, we observed an incomplete formation of the blastema at day 7 (Figure 6b). We have previously reported that MP and charge-delocalised analogues activate ERK 1/2 phosphorylation in U373MG astrocytic tumour cells. ${ }^{[55]}$ We were therefore curious to assess the effects of this bioportide upon regenerating planaria. In $\sim 50 \%$ of cases, treatment of amputees with $25 \mu \mathrm{M}$ MP resulted in partial anencephaly, though eye regeneration was still evident (Figure 6g).

Disappointingly, anterior pole and eye regeneration in those amputees treated with $25 \mu \mathrm{M}$ planarian-derived mimetic peptides, was identical to the untreated control (Figure 6a,d,e,f,h 
and i) and full regeneration of the eyespots including photoreceptors and the pigment cup were observed (Figure 6i). 


\section{DISCUSSION}

Data presented herein support the application of $S$. meditteranea, and almost certainly other planarian species, as a model organism(s) to study the import of CPPs and the discovery of bioportides capable of influencing fundamental physiological process such as regeneration and stem cell biology. Indeed, there are many additional lines of investigation which support this bold contention. In 2011 Gentile and co-authors ${ }^{[13]}$ listed a total of 29 planarian genes homologous to those encoding human proteins involved in diseases and there must surely be many more examples awaiting discovery in the $S$. mediterranea genomic database. ${ }^{[17]}$ It is also well established ${ }^{[19]}$ that there is a remarkable evolutionary conservation of pluripotency determinants in both planarian and mammalian stem cells. Specific examples of planarian homologues of human proteins studied in detail include Smed-p53, ${ }^{[56]}$ a protein which regulates self-renewal in neoblasts; Smed-TOR, ${ }^{[57]}$ a ubiquitously expressed Target of Rapamycin homologue which maintains a balance between cell division and cell death; and homologues of netrin and the netrin receptor, ${ }^{[38]}$ Smed-netrin, Smed-netR respectively, required for central nervous system regeneration. In the case of peptides, a variety of planarian hormones, neuropeptides and associated GPCRs are reported to be active in physiological process that include both cell proliferation and germline development. ${ }^{[14,18,21,22]}$

An overwhelming majority of studies employing and/or developing CPPs as delivery vectors have utilised monolayers of cultured cells. ${ }^{[1-5]}$ Hence, the S. mediterranea model described herein provides scope to address some of the more challenging obstacles, both pharmacokinetic and pharmacodynamic in origin, associated with intracellular delivery in vivo. Morphological assessment of macerated tissues identified a total of 13 basic cell types in planaria, ${ }^{[58]}$ compared with $>200$ in the human body. Considering also the relatively small size of $S$. mediterranea $(\geq 6 \mathrm{~mm}$ ), we propose that this organism is best considered a model of a single organ system. Thus, to reach intracellular sites, CPPs and bioportides must cross 
an epidermal/epithelial cell monolayer which is ciliated on the ventral surface. Our data indicate that these epithelial cells are efficiently penetrated by both CPPs and bioportides in S. mediterranea and it is noteworthy that epithelial cells surrounding organs also exhibit similar and common gross morphologies, positioning of intracellular organelles and localisation of membrane-bound receptors. ${ }^{[59]}$ We suggest that the $S$. mediterranea model also provides scope to further address the dynamic role of the epithelium in wound healing and to identify tools to explore the vital process of epithelialization.

Whilst CPP/bioportide import can be visualized in whole animals, the unpigmented blastema of $S$. mediterranea offers many advantages for microscopic studies. Fluorescent CPPs and bioportides are commonly utilized both to evaluate the kinetics and mechanisms of cellular import and to determine the distribution of peptides within complex tissues and various intracellular compartments. ${ }^{[5,47]}$ We also sought to develop a method that could be employed with a more routine confocal microscopic system. We accept that there are limitations to this system, particularly with regard to the penetration depth which can be achieved with laser microscopy, and we anticipate that the method could be modified to include more elaborate approaches such as two-photon microscopy. Such advances should also enable the positive detection of RNA-rich basophilic neoblasts, a cell population that might reasonably be expected to readily accumulate cationic peptides. N-terminal acylation of peptides on a solid phase support is also a very common and convenient approach to the generation of fluorescent analogues which also negates any potential biochemical changes that might be directly related to the choice of fluorophore conjugation site. ${ }^{[59]}$ Our selection of the red-fluorescent tetramethylrhodamine (TAMRA) chromophore, added by activation of a single isomer 6-Carboxytetramethylrhodamine, was dictated by several considerations: i) autofluorescence of planarian cells is problematic at wavelengths required to excite fluorescein conjugates; ii) TAMRA can enhance the cell-permeability of some CPP 
conjugates, compared to fluorescein ${ }^{[60]}$ but is membrane impermeable in a freely soluble form; ${ }^{[61]}$ iii) the fluorescent spectrum of TAMRA is relatively resistant to photo-bleaching during confocal analyses and mostly unaffected by other forms of interference such as cellular autofluorescence and intracellular degradation. ${ }^{[61]}$ Thus, the robust fluorescent signal that derives from TAMRA has been widely utilised to map the intracellular distribution of CPPs and biopoprtides, often in concert with organelle-specific fluorescent probes which enable co-localisation coefficients to be meaningfully determined. ${ }^{[4]}$. Relatively mild lysis conditions using sodium hydroxide were employed to quantify the intracellular uptake of TAMRA-labelled peptides into the U373MG cell line. Moreover, it is noteworthy that many alternative dyes such as fluorescein are $\mathrm{pH}$-sensitive and as such require detergent-based lysis buffers such as those evaluated by Illien and co-workers ${ }^{[62]}$ who recommend lysis conditions of $1 \mathrm{M} \mathrm{NaCl}$ and $1 \% \mathrm{NP} 40$ with sonication.

With the exception of MP, see below, none of the CPPs/bioportides compared in this investigation adversely influenced either the survival or regeneration of S. mediterranea. Thus, the relative simplicity of CPP technologies appear to be advantageous for the transepithelial delivery of bioactive agents compared with alternative strategies employing liposomes ${ }^{[64]}$ and electroporation. ${ }^{[64]}$ Those CPP, including Djeya1, which accumulated deeper along the dorsal ventral axis of the blastema show promise in targeting cellular masses other than the outer epithelial layer. Utilization of CPP technologies using the blastema as a tissue model could also provide the opportunity to target differentiating post-mitotic neoblast progeny, ${ }^{[65]}$ in addition to epithelial precursor cells or neoblast-derived mesenchymal cells. Future experiments will require specific markers and co-localization analyses to explore the destination of CPPs in planaria and further establish the blastema as a convenient in vivo complex tissue model. 
As we anticipated from the results of similar studies, ${ }^{[5,26,46]}$ planarian proteins contain many cryptic polycationic sequences that are effective CPPs within a broad dynamic range. We could have employed a QSAR prediction algorithm ${ }^{[5,44,66]}$ in an effort to more accurately define these sequences. However, in this study we deliberately adopted Futaki's approach ${ }^{[26]}$ of selecting sequences rich in Arg (and Lys) that, in the case of Ovo- and ZicA-derived CPPs, mimic DNA-binding ZF domains. One of these novel mimetic sequences, Djeya1, is a particularly efficient CPP worthy of further investigation as a broad purpose intracellular delivery vector. A second rationale for selecting CPPs from ZF domains, and the conserved EYA domain of Djeya, was to facilitate the identification of bioportides that could modulate eye regeneration following functional loss. Decapitation of planarians is a very convenient strategy to generate a relatively transparent blastema suitable for confocal analyses. However, other techniques can be utilized to enable the surgical removal of a single eye,${ }^{[67,68]}$ but it is noteworthy that the temporal regulation of planarian eye development remains constant despite variations in injury parameters or the need to simultaneously regenerate a functional brain. ${ }^{[67]}$ Employing the methodology described herein, we identified MP as a bioportide that influences head morphology. Whilst MP could induce necrosis/apoptosis of planarian cells, particularly at higher concentrations $(>10 \mu \mathrm{M})$, this observed action could also be a consequence of the activation of heterotrimeric $\mathrm{G}$ proteins ${ }^{,[53]}$ or regulation of signalling pathways mediated by ERKs. ${ }^{[54,55]}$ Further studies are necessary to clarify this intriguing observation, but we are confident that the $S$. meditterranea model will enable the identification bioportides capable of targeting and modulating the biology of planarian neoblasts and possibly other stem cells. 


\section{ACKNOWLEDGEMENTS}

The authors gratefully acknowledge the support provided by Chris Mason and CEM towards the development and maintenance of a microwave-enhanced peptide synthesis facility. Shaimaa Osman was in receipt of Newton-Mosharafa Fellowship from 2015-17. We also thank Professor Jerzy Silberring, AGH University of Science and Technology, Kraków, for the mass spectral analyses of some peptides reported in this study,

\section{CONFLICT OF INTEREST}

The authors declare no conflicts of interest. 
TABLE 1 Primary sequences and net charge of CPPs and bioportidess

\begin{tabular}{r|ll}
\multicolumn{1}{r}{ Peptide } & \multicolumn{1}{c}{ Sequence } & $\begin{array}{c}\text { Net charge } \\
(\mathbf{Z}) \boldsymbol{p H ~ 7 . 0}\end{array}$ \\
\hline $\begin{array}{r}\text { Planarian protein } \\
\text { mimetic sequences } \\
\text { Ovo1 }\end{array}$ & RKFPSKKHMQRHIRSH & 7.3 \\
Chimeric-Ovo & KFSQRKKHMKRHTRVH & 8.3 \\
ZicA1 & RRFANSSLRKKHMRVH & 7.2 \\
ZicA2 & KAFKAKYKLVNHIRVH & 6.2 \\
Djeya1 & RKLAFRYRRIKELYNSYR & 7.0 \\
CPPs & & \\
Tat & GRKKRRQRRRPPQ & 9.0 \\
C105Y & CSIPPEVKFNKPFVYLI & 1.9 \\
Bioportides & & \\
Mastoparan & INLKALAALAKKIL & 4.0 \\
Nosangiotide & RKKTFKEVANAVKISA & 5.0
\end{tabular}

All sequences are peptide amides, a modification that impacts upon the calculation of $\mathrm{Z}$ values which range from 1.9 -9.0. Planarian-derived peptides are reported here for the first time and were synthesized using the CEM Liberty Blue system. All peptides were purified to apparent homogeneity and their identity confirmed by mass spectrometry using Bruker MALDI TOF or Agilent QTOF instruments. Unless otherwise indicated, microwaveenhanced amino acid couplings utilised the routine parameters described in the methods section. Mass data and $\mathrm{z}$ values reported refer to peptides with a free $\mathrm{N}$-terminal. Ovo1, expected mass (ex.) 2072.5 Da, observed mass (ob.), 2072.4 Da. Chimeric-Ovo, $\mathrm{K}^{1}, \mathrm{~F}^{2}, \mathrm{~S}^{3}, \mathrm{Q}^{4}$ 
and $\mathrm{V}^{15}$ double coupled, ex. 2103.5 Da, ob. 2103.2 Da. Zica1, $\mathrm{V}^{15}$ double coupled, ex. 2022.4 Da, ob. 2022.4 Da. Zica2, $\mathrm{K}^{1}, \mathrm{~A}^{2}, \mathrm{~F}^{3}, \mathrm{~K}^{4}$ and $\mathrm{V}^{15}$ double coupled, ex. 1951.4, ob. 1951.2. Djeya1, ex. 2431.9 Da, ob. 2431.4 Da. The syntheses of other CPPs and bioportides are described elsewhere. ${ }^{[5,47,69]}$ 


\section{Figure Legends}

FIGURE 1 Amputation, blastema formation, anterior pole and eye regeneration in the $S$. mediterranea model. A schematic representation of novel methodologies employed to: (i) evaluate CPP import into the complex tissues of the blastema; (ii) assess the impact of planaria-derived candidate bioportides and other bioactive agents on anterior pole remodelling and eye regeneration. Upper panels show the location of the amputation site and the regenerating blastema over the course of 7 days.

FIGURE 2 CPP accumulation within blastema cells: Convenience of using the blastema compared to whole planaria. a) Living planaria were treated with TAMRA-nosangiotide (10 $\mu \mathrm{M}$ ) for $1 \mathrm{hr}$ prior to removal of mucous, fixation and bleaching. b) Cellular populations of the planarian blastema as adapted from Newmark \& Alvarado (2001). ${ }^{[50]}$ Signal to noise ratio was improved by utilizing 3 day old blastemic tissue in addition to lowering the application concentration of TAMRA-labelled CPP from $10 \mu \mathrm{M}$ to $1 \mu \mathrm{M}$ (c,d,e,f,g). TAMRAnosangiotide (c) and TAMRA-C105Y (d,e) accumulate within surface epithelial cells of the blastema following $1 \mathrm{hr}$ incubation. TAMRA-nosangiotide (f) and TAMRA-C105Y (g) also accumulate at a lower $\mathrm{Z}$ plane along the dorsal-ventral axis. Epithelial cells still visible at these lower optical planes are denoted by "e". For all blastema images, the anterior pole is to the left. Images are representative of 3 independent experiments. Scale bars (c, $20 \mu \mathrm{m}),(\mathrm{d}$, $20 \mu \mathrm{m}),(\mathrm{e}, 5 \mu \mathrm{m}),(\mathrm{f}, 200 \mu \mathrm{m})$ and $(\mathrm{g}, 50 \mu \mathrm{m})$. 
FIGURE 3 Accumulation of TAMRA-MP through the dorsal-ventral axis. Panel (a) shows the anatomical axes of the planaria. Confocal images are of the blastema only and the anterior aspect is to the left. $\mathrm{b}$ (i, ii, iii, iv and iv) show TAMRA-MP $(5 \mu \mathrm{M})$ following $1 \mathrm{hr}$ incubation accumulating within cells of the blastema at descending points along dorsal-ventral axis and the corresponding $\mathrm{Z}$ planes at which the images were captured are indicated to the right. Panels $b$ (iv) and b (v) depict images captured at a lower magnification. 3 day old blastemas were treated with TAMRA-labelled peptides prior to removal of mucous and fixation. Images are representative of 3 independent experiments.

FIGURE 4 Comparative analysis of peptide translocation efficacies into the U373MG cell line model. U373MG cells were incubated with TAMRA-labelled peptides $(5 \mu \mathrm{M})$ for $1 \mathrm{~h}$ at $37^{\circ} \mathrm{C}$. Data are expressed as mean fluorescence minus background \pm S.E.M and normalized so that the mean value for Tat is equal to $1.0, \mathrm{n}=3$.

FIGURE 5 Qualitative uptake analyses in vivo. 3 day old blastemas were treated with $5 \mu \mathrm{M}$ TAMRA-labelled planarian-derived peptides ai) Djeya1, b) Chimeric-Ovo, c) Ovo1, d) ZicA1, e) ZicA2, for $1 \mathrm{hr}$ prior to removal of mucous, fixation and confocal examination. Images are also presented here with differential interference contrast (DIC) so as to highlight the unpigmented tissue of the blastema and are representative of 3 independent experiments. aii) depicts Djeyal also accumulating at a lower $\mathrm{Z}$ plane along the dorsal-ventral axis, treatment was identical to (aii). The dorsal view is presented for all peptides except ZicA1 (d) which shows the ventral view including the pharynx. 
FIGURE 6 Eye regeneration assay. Decapitated planaria were treated with $25 \mu \mathrm{M}$ planarianderived peptides d) Djeya1, e) Ovo1, f) Chimeric-Ovo, g) MP, h) ZicA1, i) ZicA2 and blastema were allowed to regenerate. On day 7 (images shown), planaria were immobilized, euthanized and transferred into PBS for light microscopic analysis. Images were acquired with $\mathrm{x} 4, \mathrm{x} 10$ and $\mathrm{x} 20$ objectives as indicated and are representative of 6 independent experiments. U0126 (25 $\mu \mathrm{M}$ and $10 \mu \mathrm{M}$ were used as positive controls for the assay and $0.25 \%$ DMSO was included as the vehicle control for this MEK $1 / 2$ inhibitor. 


\section{Figure 1}

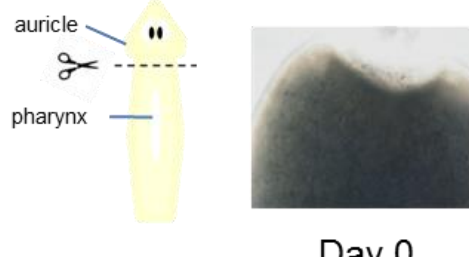

Day 0

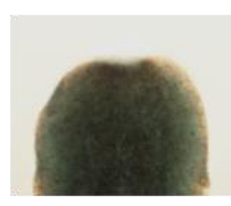

Day 1

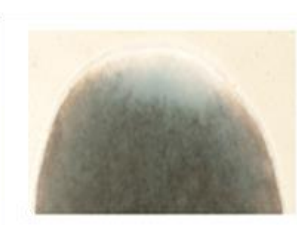

Day 3

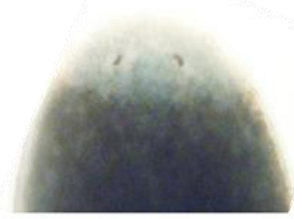

Day 7
Qualitative

uptake

analysis

Eye

regeneration

assay
Amputation

\begin{abstract}
Blastema formation and
treatment with TAMRA-

labelled peptides for 1

hour. Subsequent

demucous, fixation and

visualization
\end{abstract}

Immediately post

amputation

commence

bioportides
Additional treatments may be required depending upon the temporal nature of the targeted protein or transcription factor

Continued monitoring for morphological changes
Immobilization

demucous, killing and visualization 
Figure 2

TAMRA-nosangiotide
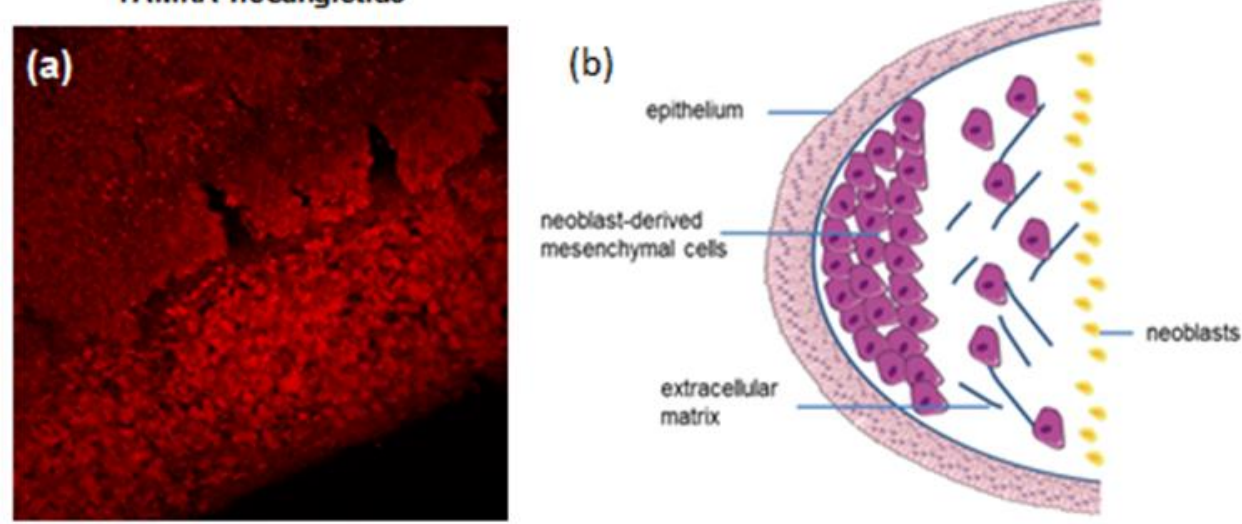

Blastema

TAMRA-nosangiotide
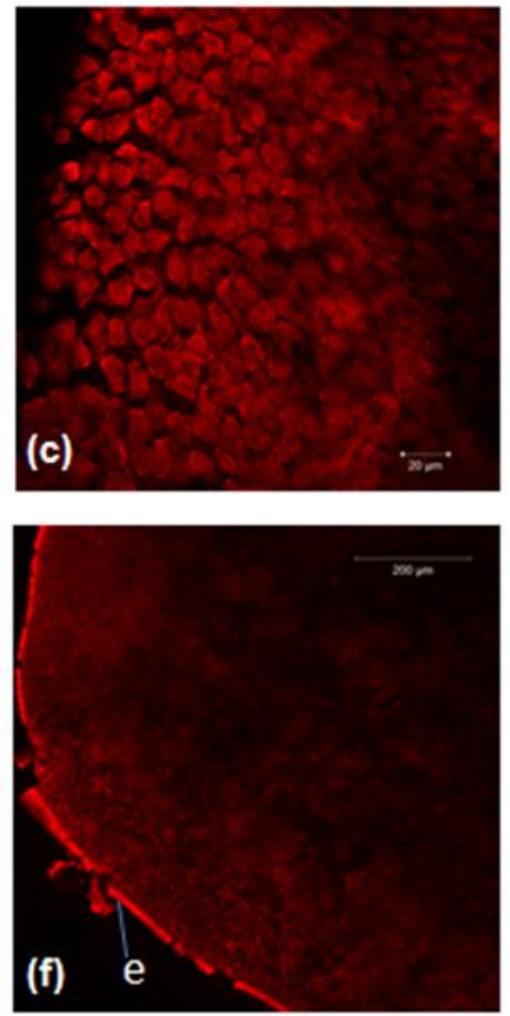

(d)

(e)

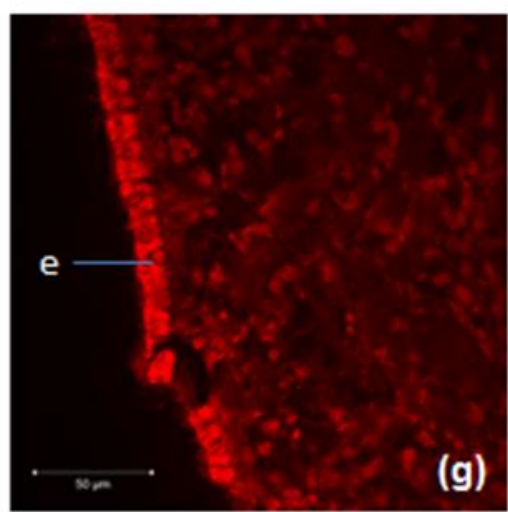


Figure 3

(a) Dorsal View
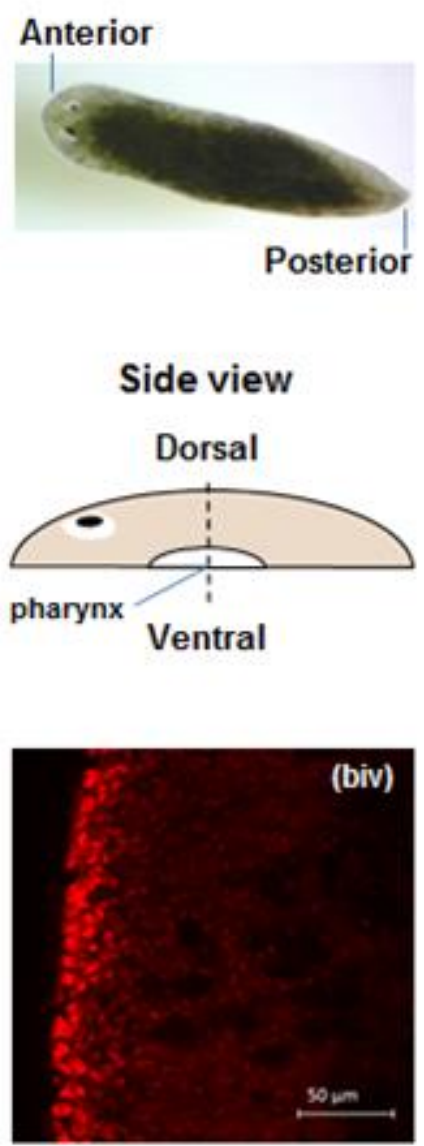

(bv)

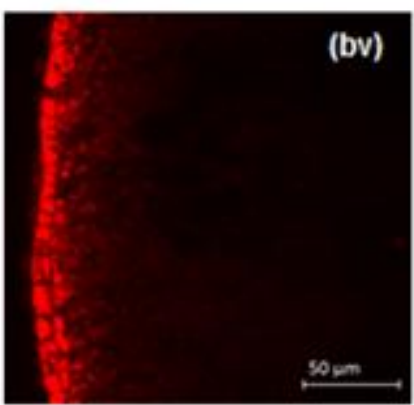

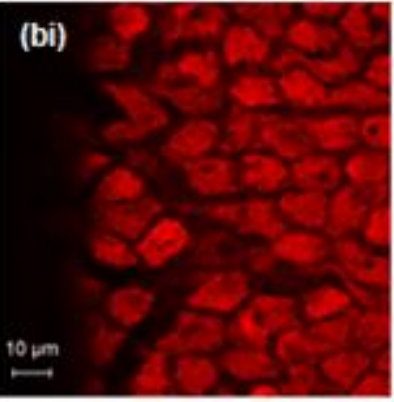
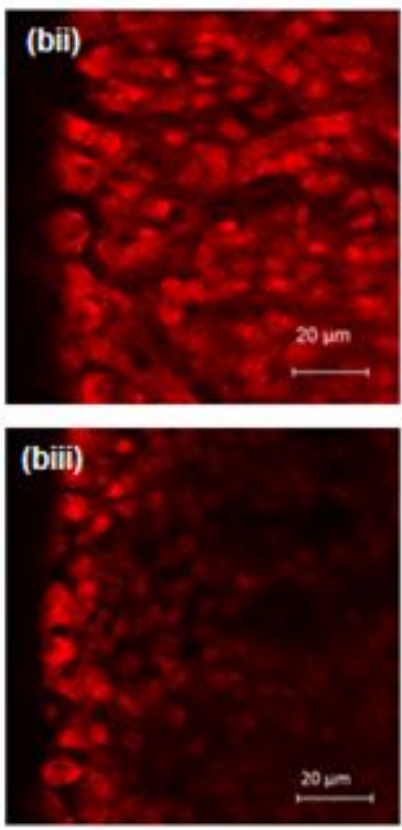

\section{Deeper} mesenchymal tissue

\section{Surface}

Epithelium

$M P ; Z=-126.4 \mu \mathrm{m}$

$M P ; Z=-120 \mu \mathrm{m}$

$\mathrm{Z}$ axis

$M P ; Z=-109 \mu \mathrm{m}$

$M P ; Z=-70.9 \mu \mathrm{m}$ 
Figure 4

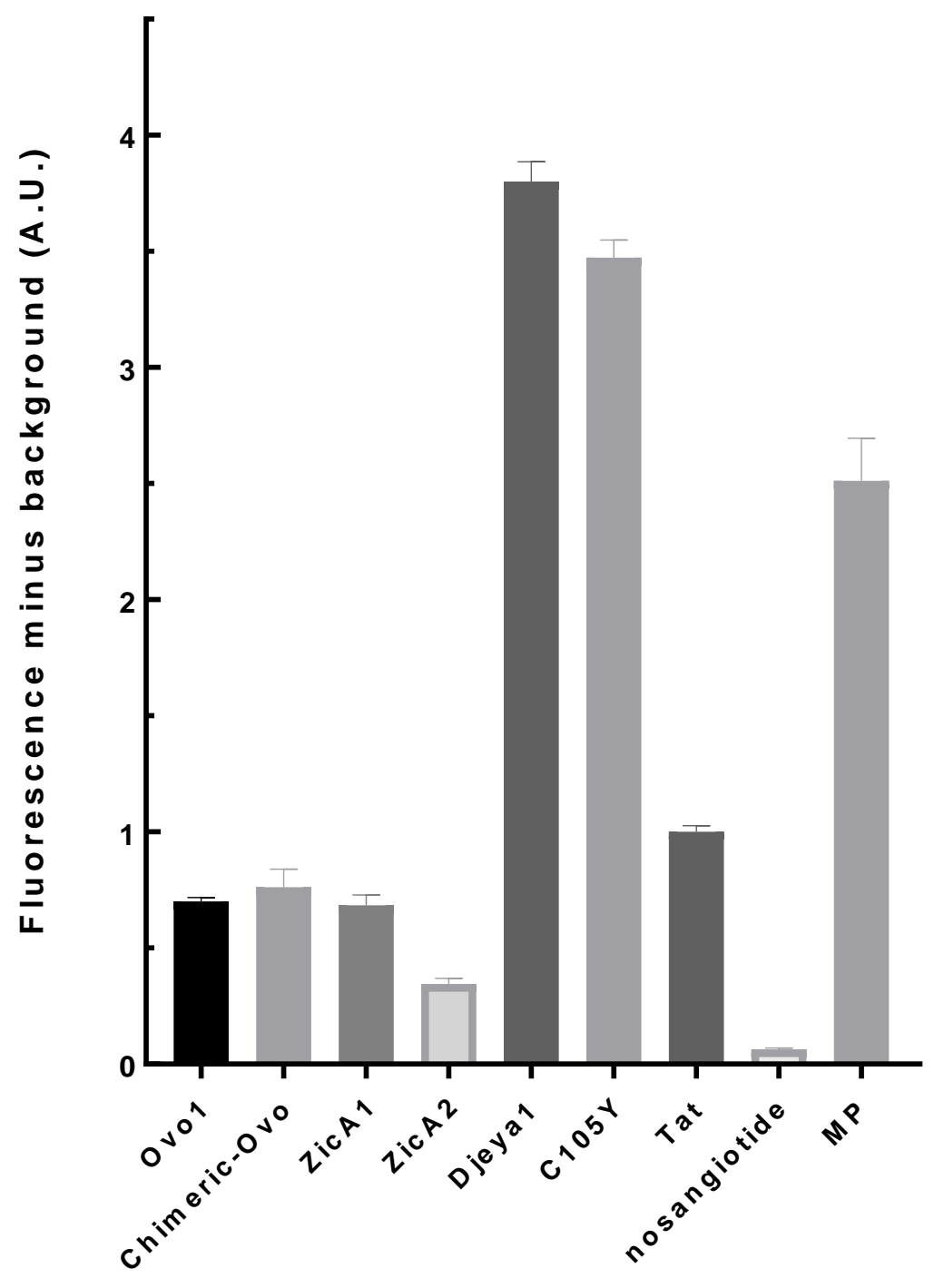


Figure 5
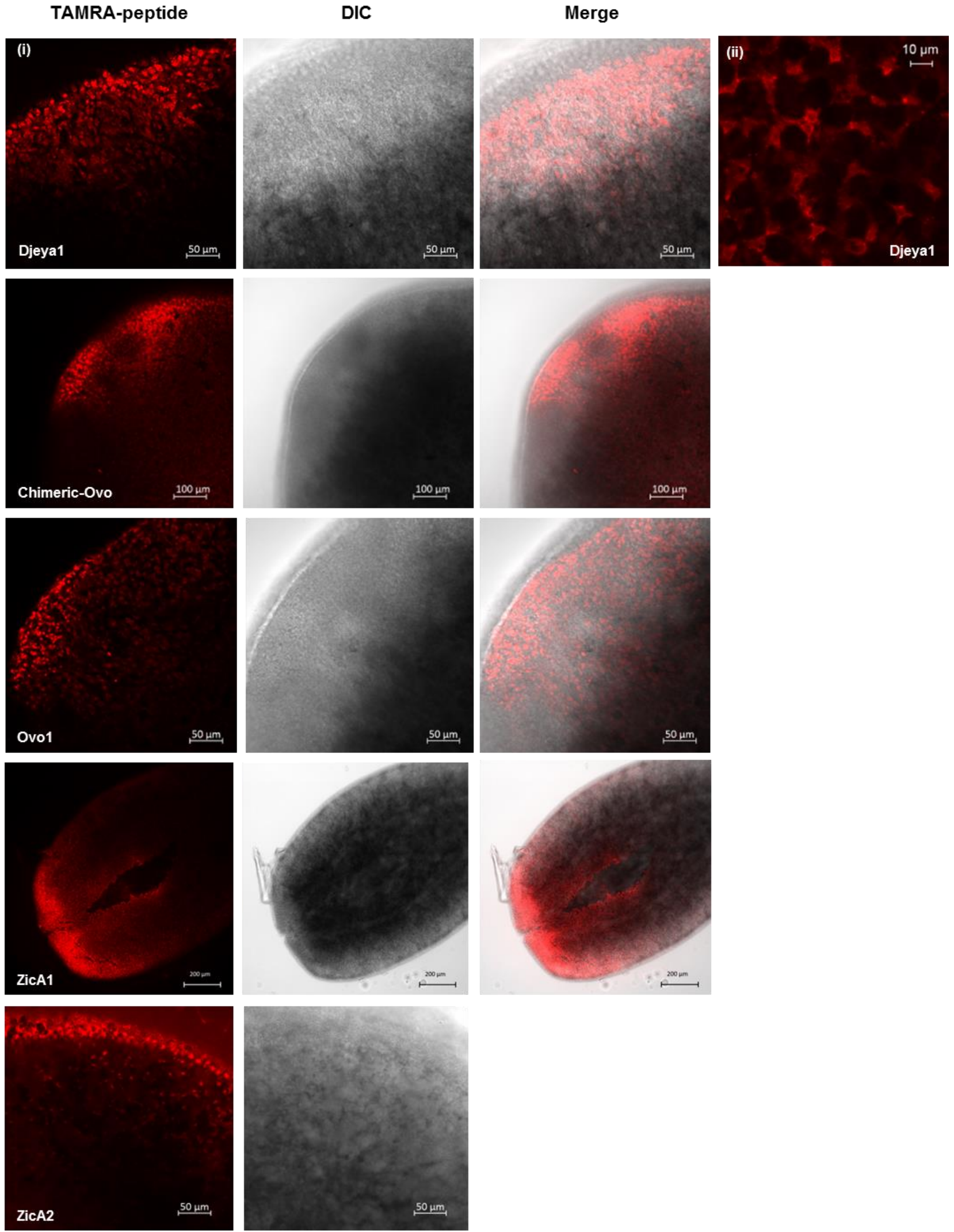
Figure 6

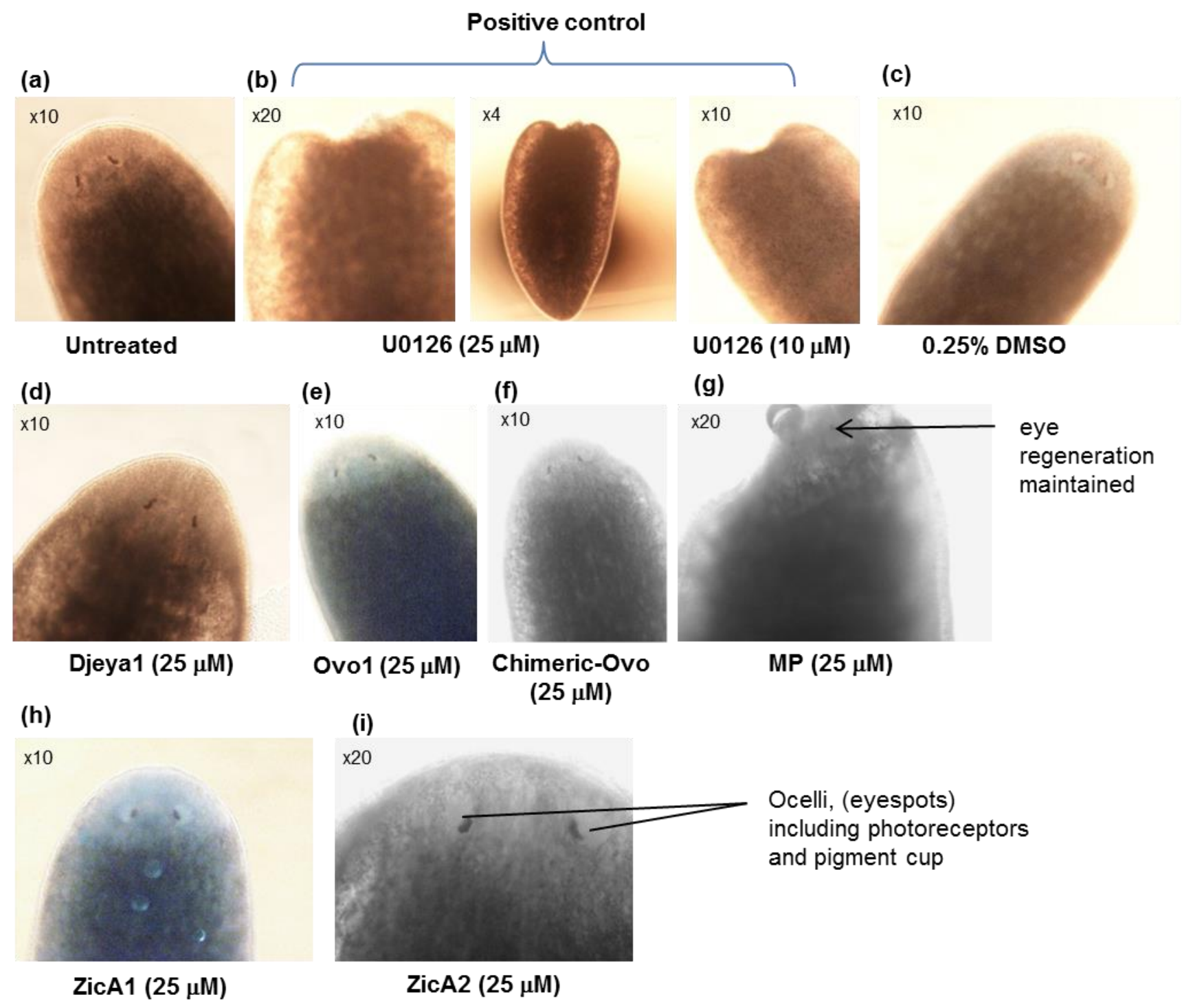




\section{REFERENCES}

[1] E. Vivés, J. Schmidt, A. Pêlegrin, Cell-penetrating and cell-targeting peptides in drug delivery. Biochim. Biophys. Acta 2008, 1786, 126-138.

[2] S.B. Fonseca, M.P. Pereira, S.O. Kelly, Recent advances in the use of cell-penetrating peptides for medical and biological applications. Adv. Drug Deliv. Rev. 2009, 6, 953-964.

[3] L.Vasconcelos, K. Pärn, Ü. Langel, Therapeutic potential of cell-penetrating peptides. Ther. Deliv. 2013, 4, 573-591.

[4] J. Howl. S. Jones, Proteomimetic cell penetrating peptides. Int. J. Pept. Res. Ther. 2008, 14, 359-366 doi: 10.1007/s10989-008-9135-2.

[5] J. Howl, S. Matou-Nasri, D.C. West, M. Farquhar, J. Slaninová, C-G. Östenson, M. Zorko, P. Östlund, S. Kumar, Ü. Langel, J. McKeating, S. Jones, Bioportide: an emergent concept of bioactive cell-penetrating peptides. Cell. Mol. Life Sci. 2012, 69, 2951-2966. doi: $10.1007 / \mathrm{s} 00018-012-0979-4$.

[6] J. Howl, S. Jones, Insights into the molecular mechanisms of action of bioportides: a strategy to target protein-protein interactions. Expert Rev. Mol. Med. 2015, 17, e1. doi: 10.1017/erm.2014.24.

[7] C. Foged, H.M. Nielsen, Cell-penetrating peptides for drug delivery across membrane barriers. Expert Opin. Drug Deliv. 2008, 5, 105-117. 
[8] L-L. Zou, J-L. Mu, T. Wang, T-B. Yang, C-B. Liu, Cell-penetrating peptide-mediated therapeutic molecule delivery into the central nervous system. Curr. Neuropharmacol. 2013, 11, 197-208. doi: 10.2174/1570159X11311020006

[9] S. Staiman, N. Bracke, E. Wynerdaele, B. Gevaert, K. Peremans, C. Burvenich, I. Polis, B. De Spiegeleer, Cell-penetrating peptides selectively cross the blood-brain barrier in vivo. PLoS ONE 2015, 10, e0139652. doi: 10.1371/journal.pone.0139652.

[10] K., Kurikoff, M. Gestin, Ü. Langel, Recent in vivo advances in cell-penetrating peptideassisted drug delivery. Expert Opin. Drug Deliv. 2016, 13, 373-87. doi: 10.1517/17425247.2016.1125879.

[11] A. Sánchez Alvarado, Stem cells and the planarian Schmidtea mediterranea. C. R. Biol. 2007, 330, 498-503. doi: 10.1016/j.crvi.2007.05.005.

[12] A.A. Aboobaker, Planarian stem cells: a simple paradigm for regeneration. Trends Cell. Biol. 2011, 21, 304-311. doi: 10.1016/j.tcb.2011.01.005

[13] L. Gentile, F. Cebrià, K. Bartscherer, The planarian flatworm: an in vivo model for stem cell biology and nervous system regeneration. Dis. Model. Mech. 2011, 4, 12-19. doi: 10.1242/dmm.006692.

[14] J. Baguñà, E., Salö, R. Romero, Effects of activators and antagonists of the neuropeptides substance $\mathrm{P}$ and substance $\mathrm{K}$ on cell proliferation in planarians Int. J. Dev. Biol. 1989, 33, 261-266. 
[15] J.M. Martín-Durán, F. Monjo, R. Romero, Planarian embryology in the era of comparative developmental biology. Int. J. Dev. Biol. 2012, 56, 39-48. doi: 10.1387/ijdb.113442jm.

[16] I.M. Sheiman, N.D. Kreshchenko, Regeneration of planarians: Experimental object. Russ. J. Dev. Biol. 2015, 46, 1-9.

[17] S.M.C. Robb, K. Gotting, E. Ross, A.A. Alvarado, SmedGD 2.0: the Schmidtea mediterranea genome database.Genesis 2105, 53, 535-546.

[18] M. Zamanian, M.J. Kimber, P. McVeigh, S.A. Carlson, S.A. Maule, T.A. Day, The repertoire of G protein-coupled receptors in the human parasite Schistosoma mansoni and the model organism Schmidtea mediterranea. BMC Genomics 2011, 12, 596. doi: 10.1186/14712164-12-596.

[19] P. Önal, D. Grün, C. Adamidi, A. Rybak, J. Solana, G. Matrobuoni, Y. Wang, H-P, Rahn, W. Chen, S. Kempa, U. Ziebold, N. Rajewsky, Gene expression of pluripotency determinants is conserved between mammalian and planarian stem cells. EMBO J. 2012, 31, 2755-2769. doi: 10.1038/emboj.2012.110.

[20] S.W. Laplan, P.W. Reddien, Transcriptome analysis of the planarian eye identifies ovo as a specific regulator of eye regeneration. Cell Rep. 2012, 2, 294-307.

[21] J.J. Collins III, X. Hou, E.V. Romanova, B.G. Lambrus, C.M. Miller, A. Saberi, J.V. Sweedler, P.A. Newmark, Genome-wide analyses reveal a role for peptide hormones in 
planarian germline development. PLoS Biol 2010, 8, e1000509. doi:

10.1371/journal.pbio.1000509.

[22] C.M. Miller, P.A. Newmark, An insulin-like peptide regulates size and adult stem cells in planarians. Int. J. Dev. Biol. 2012, 56, 75-82. doi: 10.1387/ijdb.113443cm.

[23] T-H. Ong, E.V. Romanova, R.H. Roberts-Galbraith, N. Yang, T.A. Zimmerman, J.J. Collins III, J.E. Lee, N.L. Kellehe, P.A. Newmark, J.V. Sweedler, Mass spectrometry imaging and identification of peptides associated with cephalic ganglia regeneration in Schmidtea mediterranea. J. Biol. Chem. 2016, 291, 8109-8120. doi: 10.1074/jbc.M115.709196.

[24] D.G. Bocchinfuso, P. Taylor, E. Ross, V. Ignatchenko, T. Kislinger, B.J. Pearson, F. Moran, Proteomic profiling of the planarian Schmidtea mediterranea and its mucous reveals similarities with human secretions and those predicted for parasitic flatworms. Mol. Cell. Proteomics 2012, 11, 681-91. doi: 10.1074/mcp.M112.019026.

[25] M. Kristensen, D. Birch, H.M. Nielsen, Applications and challenges for use of cellpenetrating peptides as delivery vectors for peptide and protein cargos. Int. J. Mol. Sci. 2016, 17, 185. doi: 10.3390/ijms17020185.

[26] S. Futaki, T. Suzuki, W. Ohashi, T. Yagami, S. Tanaka, K. Ueda, Y. Sugiura, Argininerich peptides. An abundant source of membrane-permeable peptides having potential as carriers for intracellular protein delivery. J. Biol. Chem. 2001, 276, 5836-5840. 
[27] J. Cronican, K.T. Beier, T.N. Davis, J.C. Tseng, W. Li, D,B. Thompson, A.F. Shih, E.M. May, C.L. Cepko, A.L. Kung, Q. Zhou, D.R. Liu, A class of human proteins that deliver functional proteins into mammalian cells in vitro and in vivo. Chem. \& Biol. 2011, 18, 833838. doi: 10.1016/j.chembiol.2011.07.003.

[28] E. Vivès, P. Brodin P, B. Lebleu, A truncated HIV-1 Tat protein basic domain rapidly translocates through the plasma membrane and accumulates in the cell nucleus. J. Biol. Chem. 1997, 272, 16010-16017.

[29] D. Derossi, A.H. Joliot, G. Chassaing, A. Prochiantz, The third helix of the Antennapedia homeodomain translocates through biological membranes. J. Biol. Chem. 1994, 269, 10444-10450.

[30] L. Mannini, L. Rossi, P. Deri, V. Gremigni, A. Salvetti, E. Saló, R. Batistoni, Djeyes absent (Djeya) controls prototypic planarian eye regeneration by cooperating with the transcription factor Djsix-1. Dev. Biol. 2004, 269, 346-359.

[31] C. Vásquez-Doorman, C.P. Petersen, zic-1 expression in planarian neoblasts after injury controls anterior pole regeneration. PLOS Genet. 2014, 10, e1004452. doi: org/10.1371/journal.pgen.1004452.

[32] Vogg, M.C., Owlarn, S., Y.A. Pérez Rico, J. Xie, Y. Suzuki, L. Gentile, W. Wu, K. Bartscherer, Stem cell-dependent formation of a functional anterior regeneration pole in planarians requires Zic and Forkhead transcription factors. Dev. Biol. 2014, 390, 136-148. doi: 10.1016/j.ydbio.2014.03.016. 
[33] P.X. Xu, W. Zheng, C. Laclef, P. Maire, R.L. Maas, H. Peters, X. Xu, Eya1 is required for the morphogenesis of mammalian thymus, parathyroid and thyroid. Development 2002, $129,3033-3044$

[34] J. Baguñà, The planarian neoblast: the rambling history of its origin and some current black boxes. Int. J. Dev. Biol. 2012, 56, 19-37. doi: 10.1387/ijdb.113463jb.

[35] D. Kim, C-H. Kim, J-I. Moon, Y-G. Chung, M-Y. Chang, B-S. Han, S. Ko, E. Yang, K.Y. Cha, R. Lanzar, K-S. Kim, Generation of human induced pluripotent stem cells by direct delivery of reprogramming proteins. Cell Stem Cell, 2009, 4, 472-476. doi: 10.1016/j.stem.2009.05.005.

[36] T. Kaitsuka, K. Tomizawa, Cell-penetrating peptide as a means of directing the differentiation of induced-pluripotent stem cells.Int. J. Mol. Sci. 2015, 16, 26667-26676. doi: 10.3390/ijms 161125986.

[37] J. Solana, D. Kao, Y. Mihaylova, F. Jaber-Hijazi, S. Malla, R. Wilson, A. Aboobaker, Defining the molecular profile of planarian pluripotent stem cells using a combinatorial RNA-seq, RNA interference and irradiation approach. Genome Biol. 2012, 13, R19. doi: 10.1186/gb-2012-13-3-r19.

[38] F. Cebrià, P.A. Newmark, Planarian homologs of netrin and netrin receptor are required for proper regeneration of the central nervous system and the maintenance of nervous system architecture. Development 2005, 132, 3691-3703. 
[39] S. Jones, S. Osman, J. Howl, A high-throughput synthetic platform enables the discovery of proteomimetic cell penetrating peptides and bioportides. Int. J. Pept. Res. Ther. 2018, doi: 10.1007/s10989-018-9681-1.

[40] R. Subirs-Funosas, R. Prohens, R. Barbas, A. El-Faham, F. Albericio, Oxyma: an efficient additive for peptide synthesis to replace the benzotriazole-based HOBt and HOAt with a lower risk of explosion. Chemistry 2009, 15, 9394-9403. doi: 10.1002/chem.200900614.

[41] Z. Dong, Y. Yuwen, Q. Wang, G. Chen, D. Liu, Eight genes expression patterns during visual system regeneration in Dugesia japonica. Gene Expr. Patterns, 2012, 12, 1-6. doi: org/10.1016/j.gep.2011.08.001.

[42] S.D. Cross, A.A. Johnson, B.J. Gilles, L.A. Bachman, T. Inoue, K. Agata, L.Y. Marmorstein, A.D. Marmorstein, Control of maintenance and regeneration of planarian eyes by ovo. Invest. Opthalmol. Vis. Sci. 2015, 56, 7604-7610. doi: 10.1167/iovs.15-17458.

[43] B.J. Pearson, G.T. Eisenhoffer, K.A. Gurley, J.C. Rink, D.E. Miller, A. Sánchez Alvarado, Formaldehyde-based whole-mount in situ hybridization method for planarians. Dev. Dyn. 2009, 238, 443-450. doi: 10.1002/dvdy.21849.

[44] S. Jones. T. Holm, I. Mäger, Ü. Langel, J. Howl, Characterization of bioactive cell penetrating peptides from human cytochrome c: protein mimicry and the development of a 
novel apoptogenic agent. Chem. \& Biol. 2010, 17, 735-744. doi:

10.1016/j.chembiol.2010.05.018.

[45] U. Soomets, M. Lindgren, X. Gallet, M. Hällbrink, A. Elmquist, L. Balaspiri, M. Zorko M. Pooga, R. Brasseur, Ü. Langel, Deletion analogues of transportan. Biochim. Biophys. Acta. 2000, 1467, 165-176.

[46] S. Jones, C. Martel, A-S. Belzacq-Casagrande, C. Brenner, J. Howl, Mitoparan and target-selective chimeric analogues: Membrane translocation and intracellular redistribution induces mitochondrial apoptosis. Biochim. Biophys. Acta. Mol. Cell Res. 2008, 1783, 849863. doi: org/10.1016/j.bbamcr.2008.01.009.

[47] S. Jones, J. Uusna, Ü. Langel, J. Howl, Intracellular target-specific accretion of cell penetrating peptides and bioportides: Ultrastructural and biological correlates. Bioconjugate Chem. 2016, 27, 121-129. doi: 10.1021/acs.bioconjchem.5b00529.

[48] S. Owlarn, K. Bartscherer, Go ahead, grow a head! A planarian's guide to anterior regeneration. Regeneration, 2016, 24, 139-155. doi: 10.1002/reg2.56.

[49] M. Rhee, P. Davis, Mechanism of uptake of C105Y, a novel cell-penetrating peptide. $J$. Biol. Chem. 2006, 281, 1233-1240.

[50] P. Newmark, A. Sánchez Alvarado, Regeneration in Planaria. Biol. Rev. 2001, 30, doi: 10.1038/npg.els.0001097. 
[51] I. Hori, Observations on planarian epithelization after wounding. J. Submicrosc. Cytol. Pathol. 1989, 21, 307-315.

[52] E. Saló, J. Baguñà, Regeneration and pattern formation in planarians. I. The pattern of mitosis in anterior and posterior regeneration in Dugesia $(\mathrm{G})$ tigrina, and a new proposal for blastema formation. J. Embryol. Exp. Morphol. 1984, 83, 63-80.

[53] M. Sukumar, T. Higashijima, G protein-bound conformation of mastoparan-X, a receptor-mimetic peptide. J. Biol. Chem. 1992, 267, 21421-21424.

[54] J. Tasaki, N. Shibata, O. Nishimura, K. Itomi, Y. Tabata, F. Son, N. Suzuki, R. Araki, M. Abe, K. Agata, Y. Umesono, ERK signaling controls blastema cell differentiation during planarian regeneration. Development, 2011, 138, 2417-2427. doi: 10.1242/dev.060764.

[55] S. Jones, M. Farquhar, A. Martin, J. Howl, Intracellular translocation of the decapeptide carboxyl terminal of Gi3 $\alpha$ induces the dual phosphorylation of p42/p44 MAP kinases. Biochim. Biophys. Acta. Mol. Cell Res. 2005, 1745, 207-214.

[56] B. J. Pearson, A. Sánchez Alvarado, A planarian p53 homolog regulates proliferation and self-renewal in adult stem cell lineages. Development, 2010, 137, 213-221. doi: 10.1242/dev.044297.

[57] T.H. Peiris, F. Weckerle, E. Ozamoto, D. Ramirez, D. Davidian, M.E. Garcia-Ojeda, Ne. J. Oviedo, TOR signaling regulates planarian stem cells and controls localized and organismal growth. J. Cell Sci. 2012, 125, 1657-1665. doi: 10.1242/jcs.104711. 
[58] J. Baguñà, R. Romero, Quantitative analysis of cell types during growth, degrowth and regeneration in the planarians Dugesia mediterranea and Dugesia tigrina. Hydrobiologia, 1981, 84, 181-194,

[59] N. Muthukrishnan, S. Donovan, J-P. Pellois,,The photolytic activity of poly-arginine cell penetrating peptides conjugated to carboxy-tetramethylrhodamine is modulated by arginine residue content and fluorophore conjugation site. Photochem. Photobiol. 2014, 90, 10341042. doi: 10.1111/php.12288.

[60] R. Fischer, T. Waizenegger, R. Köhler, R. Brock, (2002). A quantitative validation of fluorophore-labelled cell-permeable peptide conjugates: fluorophore and cargo dependence of import. Biochim. Biophys. Acta, 2002, 1564, 365-374.

[61] J. He, K. Hristova, W.C. Wimley, A highly charged voltage-sensor helix spontaneously translocates across membranes. Angew. Chem. 2012, 124, 7262-7765. doi: 10.1002/ange.201202741.

[62] F. Illien, N. Rodriguez, M. Amoura, A. Joliot, M. Pallera, S. Cribier, F. Burlina, S. Sagan, Quantitative fluorescence spectroscopy and flow cytometry analyses of cellpenetrating peptides internalization pathways: optimization, pitfalls, comparison with mass spectrometry quantification. Sci. Rep. 2016, 14, 36938. doi: 10.1038/srep36938.

[63] V. Sasidharan, S. Marepally, S.A. Elliot, S. Baid, V. Lakshmanan, N. Nayar, D. Bansal, A. Sánchez Alvarado, P. K. Vemula, D. Palakodeti, The miR-124 family of microRNAs is 
crucial for regeneration of the brain and visual system in the planarian Schmidtea mediterranea. Development, 2017, 144, 3211-3223. doi: 10.1242/dev.144758.

[64] C. González-Estévez, T. Momose, W.J. Gehring, E. Saló, Transgenic planarian lines obtained by electroporation using transposon-derived vectors and an eye-specific GFP marker. Proc. Natl. Acad. Sci. USA, 2003, 100, 14046-14051. doi: org/10.1073/pnas.2335980100.

[65] G.T. Eisenhoffer, H. Kang, A. Sánchez Alvarado, Molecular analysis of stem cells and their descendants during cell turnover and regeneration in the planarian Schmidtea mediterranea. Cell Stem Cell. 2008 3, 327-339. doi: 10.1016/j.stem.2008.07.002.

[66] M. Hällbrink, K. Kilk, A. Elmquist, P. Lundberg, M. Lindgren, Y. Jiang, M. Pooga, U. Soomets, Ü. Langel, Prediction of cell-Penetrating peptides. Int. J. Pept. Res. Ther. 2005, 11, 249-259.

[67] M.E. Deochand, T.R. Birkholz, W.S. Beane, Temporal regulation of planarian eye regeneration. Regeneration, 2016, 3, 209-221.

[68] J.M. Morton, M.A. Saad, W.S. Beane, Surgical ablation assay for studying eye regeneration in planarians. J. Vis. Exp. 2017, e55594. doi: 10.3791/55594.

[69] S. Jones, M. Lukanowska, J. Suhorutsenko, S. Oxenham, C. Barratt, S. Publicover, D.M. Copolovici, Ü. Langel,. J. Howl, Intracellular translocation and differential accumulation of cell-penetrating peptides in bovine spermatozoa: evaluation of efficient delivery vectors that 
do not compromise human sperm motility. Hum. Reprod. 2013, 28, 1874-1889. doi: 10.1093/humrep/det064. 